\title{
Small punch creep of Fe-Al-Cr alloy with Ce addition and its relation to uniaxial creep tests
}

\author{
F. Dobeš* , P. Dymáček, M. Friák \\ Institute of Physics of Materials, Academy of Sciences of the Czech Republic, Žižkova 22, 61662 Brno, Czech Republic
}

Received 4 April 2018, received in revised form 8 June 2018, accepted 2 July 2018

\begin{abstract}
Creep behaviour of the alloy based on intermetallic compound $\mathrm{Fe}_{3} \mathrm{Al}$ with additions of 2.6 at.\% chromium and 0.02 at.\% cerium was studied at temperatures from 500 to $800^{\circ} \mathrm{C}$ by small punch testing with a constant force. The dependences of the minimum deflection rate and the time to rupture on the applied force follow similar dependences obtained in uniaxial creep tests of the same alloy. The results of small punch tests can be explained by the existence of different crystal lattices occurring at different temperatures. It is shown that the force applied in the small punch test can be successfully converted into the equivalent applied stress using the empirical formula suggested by the new European standard for small punch testing. The minimum deflection rate can be converted into the minimum creep strain rate as well. The improvement of the latter conversion based on the Monkman-Grant relationship is proposed.
\end{abstract}

K e y w o r d s: iron aluminides, creep, small punch test, Monkman-Grant relation

\section{Introduction}

Alloys based on intermetallic iron and aluminium compounds, $\mathrm{Fe}_{3} \mathrm{Al}$ and $\mathrm{FeAl}$, are known for many excellent properties like resistance to oxidation and corrosion in various molten salts, relatively low density, electrical resistivity, low cost of raw materials, etc. [1-3]. One of the goals of current research is to improve their mechanical properties at elevated temperatures. Creep resistance can be increased by addition of various alloying elements that lead to solid solution hardening, to precipitation strengthening or to strengthening by order $[4,5]$. Moreover, different heat treatment procedures [6] and preparation techniques (reactive squeeze infiltration [7], laser additive manufacturing [8]) can also contribute to the progress in the development of this class of alloys.

The growing number of alloying elements and preparation modalities enormously increases the number of laboratory alloys required to design the route to an optimal constitution. A reliable method for testing small specimens is thus highly desirable. One of such modern methods is small punch testing [9-11]. The testing is especially suitable when the volume of mate- rial is limited and standard type specimen cannot be manufactured, e.g., characterizing heat affected zones in welds $[12-14]$ or when it is necessary to minimize the radiation activity in monitoring structural integrity of nuclear components [15].

A main problem of the small punch test is the transformation of basic variables of the test, i. e., force, deflection, and deflection rate, to variables of conventional uniaxial tests, i.e., stress, strain, and strain rate. In soon to be published new European standard [16, 17], the solution of the problem related to creep properties is based on an analysis of a large dataset of both conventional and small punch tests. The used set contains entirely results relevant to heat-resistant steels: low alloy, 9-12Cr, and austenitic steels. It is the purpose of the present paper to examine the eligibility of procedures suggested by the prepared standard for the research of advanced Fe-Al based alloy. The tested alloy contains additions of chromium and cerium. Chromium increases room temperature ductility, but it has a negligible effect on strength [18]. On the other hand, small amounts of cerium are beneficial for enhancement of both room temperature ductility and elevated temperature strength [19].

*Corresponding author: author: e-mail address: dobes@ipm.cz 
Table 1. The chemical composition of the studied alloy (at.\%)

\begin{tabular}{cccccc}
\hline $\mathrm{Fe}$ & $\mathrm{Al}$ & $\mathrm{Cr}$ & $\mathrm{Mn}$ & $\mathrm{Ce}$ & $\mathrm{C}$ \\
\hline 68.42 & 28.4 & 2.6 & 0.4 & 0.02 & 0.16 \\
\hline
\end{tabular}

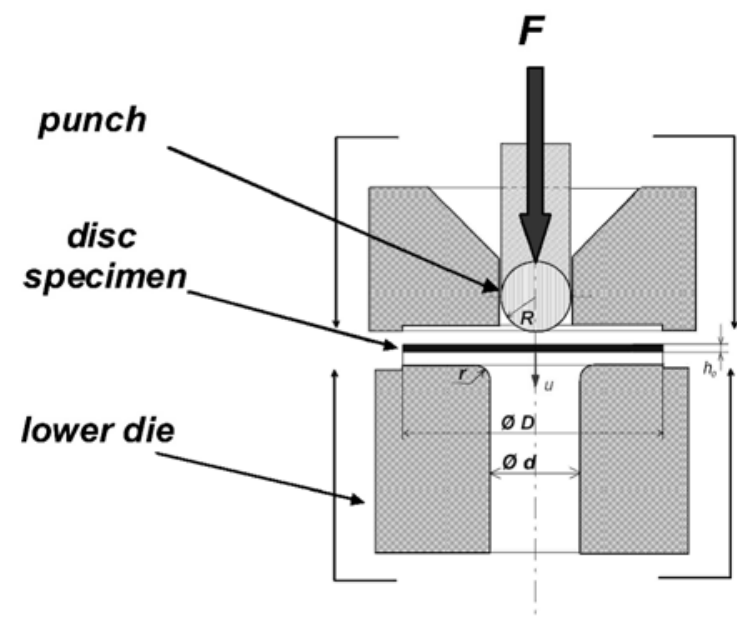

Fig. 1. Schematic of small punch test setup.

\section{Experimental procedure}

The alloy was melted in a vacuum furnace and cast in an argon atmosphere at the Research Institute of Metals, Ltd., Panenské Břežany. The rolling of the original sheet (thickness $40 \mathrm{~mm}$ ) to the final one $(13 \mathrm{~mm})$ was performed at $1100^{\circ} \mathrm{C}$. Finally, the sheet was quenched in oil. The composition of the alloy is given in Table 1. Details of its microstructure can be found elsewhere [20]. The mean value of the ultimate tensile strength at room temperature was approximately $625 \mathrm{MPa}$; the yield stress was equal to $340 \mathrm{MPa}[21]$.

The specimens for small punch testing were prepared by machining cylinders $8 \mathrm{~mm}$ in diameter. The cylinders were subsequently cut to slices $1.2 \mathrm{~mm}$ thick using electro-discharge machining. The slices were ground carefully from both sides equally and finally polished to 1200 grit. The final thickness of 0.500 $\pm 0.002 \mathrm{~mm}$ was measured by using a micrometer with a resolution of $1 \mu \mathrm{m}$. For small punch testing, a constant load cantilever creep machine was adapted. During the test, a precise ceramic ball made of FRIALIT F99.7, $2.5 \mathrm{~mm}$ in diameter, is pushed with a constant force against a specimen supported by a 4 -mm diameter receiving die (lower die), cf. Fig. 1. The technique is described in more detail elsewhere [22]. Tests were performed at temperatures ranging from 500 to $800^{\circ} \mathrm{C}$ and applied forces from $40 \mathrm{~N}$ to $500 \mathrm{~N}$. It was not pos-

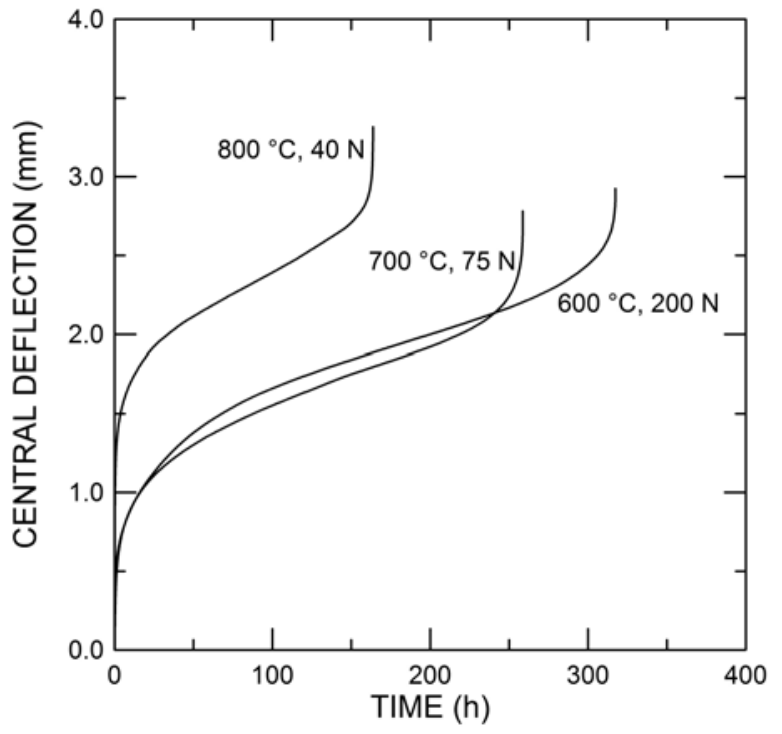

Fig. 2. Examples of small punch creep curves.

sible to use the same applied force for testing at different temperatures in the whole range of temperatures due to a steep dependence of the time to fracture on temperature and due to time limitation of small punch tests. For a direct comparison with uniaxial tests, the results of conventional creep tests in tension - performed on the same sheet - published in the present journal are used [23].

\section{Results}

Examples of the dependence of central deflection vs. time obtained in the small punch tests are given in Fig. 2. The tests of comparable durations at different temperatures in the range of existence of B2 lattice were selected for the illustration. It can be seen that the same general features of the curves can be observed as in conventional creep tests. In the primary stage, the deflection rate decreases till the minimum rate is reached. After that, the deflection rate is steadily increasing, and finally, the rupture of disc happens. It can be seen that the two main quantities of the small punch test, i.e., the minimum deflection rate and the time to rupture, can be easily evaluated.

The dependence of the minimum deflection rate on the applied force for different temperature levels is given in Fig. 3 in bi-logarithmic coordinates. The dependence can be described by the power-law relationship of the form:

$$
\dot{u}_{\mathrm{m}}=A_{\mathrm{m}} F^{n_{\mathrm{m}}},
$$

where $\dot{u}_{\mathrm{m}}$ is the minimum deflection rate, $F$ is the acting force, $n_{\mathrm{m}}$ is a force exponent and $A_{\mathrm{m}}$ is a tem- 


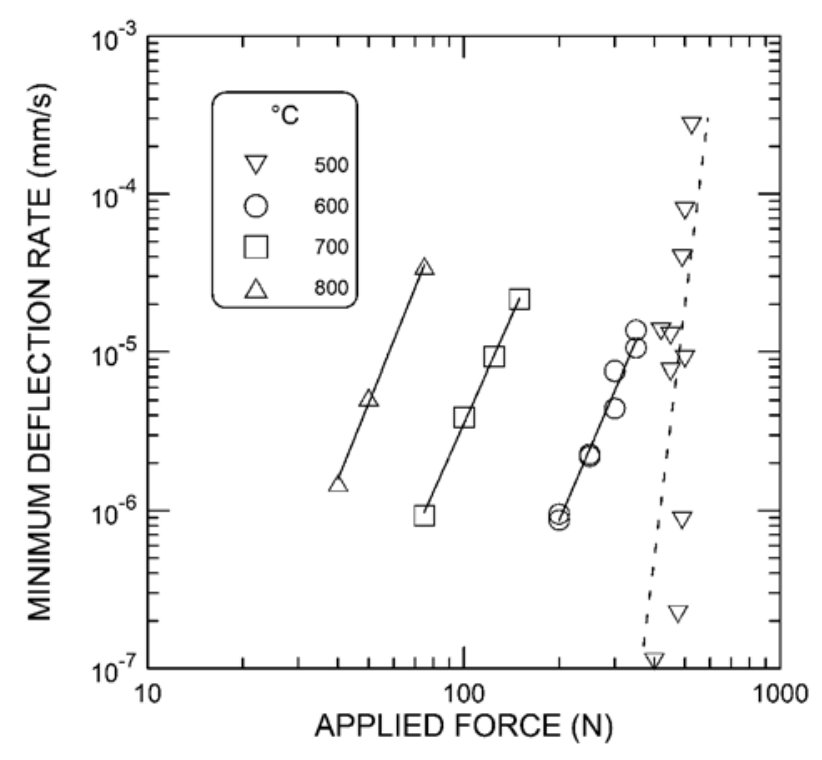

Fig. 3. Dependence of minimum deflection rate on applied force.

perature dependent parameter. Two different quantitative features can be observed. In the temperature range from 600 to $800{ }^{\circ} \mathrm{C}$ the values of force exponent $n_{\mathrm{m}}$, found by the least squares method, equal approximately 4.5 to 5.0 . In the case of conventional uniaxial creep tests, such values are typical for power-law creep in single phase compounds, pure metals and solid solutions of the metal-type [24]. At a temperature of $500{ }^{\circ} \mathrm{C}$, the value of the force exponent is substantially greater, $n_{\mathrm{m}}>16$. This is in agreement with the negligible dependence of the yield stress on the strain rate at temperatures up to $520^{\circ} \mathrm{C}$ reported for the similar alloy by Karlík et al. [25].

The observed difference reflects the existence of two types of crystal lattice occurring in the present alloy in the studied temperature range. At temperatures above $540^{\circ} \mathrm{C}$, the ordered $\mathrm{FeAl}$ phase with $\mathrm{B} 2$ lattice exists, whereas at lower temperatures the stable compound is ordered $\mathrm{Fe}_{3} \mathrm{Al}$ with $\mathrm{D}_{3}$ lattice [26]. The large value of the exponent $n_{\mathrm{m}}$ in the $\mathrm{D}_{3}$ area can perhaps be attributed to a reduced ductility in this temperature range: this reduction probably causes early onset of tertiary creep and thus an increase of the measured minimum deflection rate at higher forces.

The dependence of the time to rupture $t_{\mathrm{R}}$ on the applied force is given in Fig. 4. The dependence can also be described by a power law of the same type as Eq. (1):

$$
t_{\mathrm{R}}=A_{\mathrm{R}} F^{n_{\mathrm{R}}},
$$

with negative values of the exponent $n_{R}$. The figure confirms the division into two areas with different crystal lattices. In the temperature range of existence of $\mathrm{B} 2$ lattice the power $n_{\mathrm{R}}$ is from -4.2 to -4.8 . At a

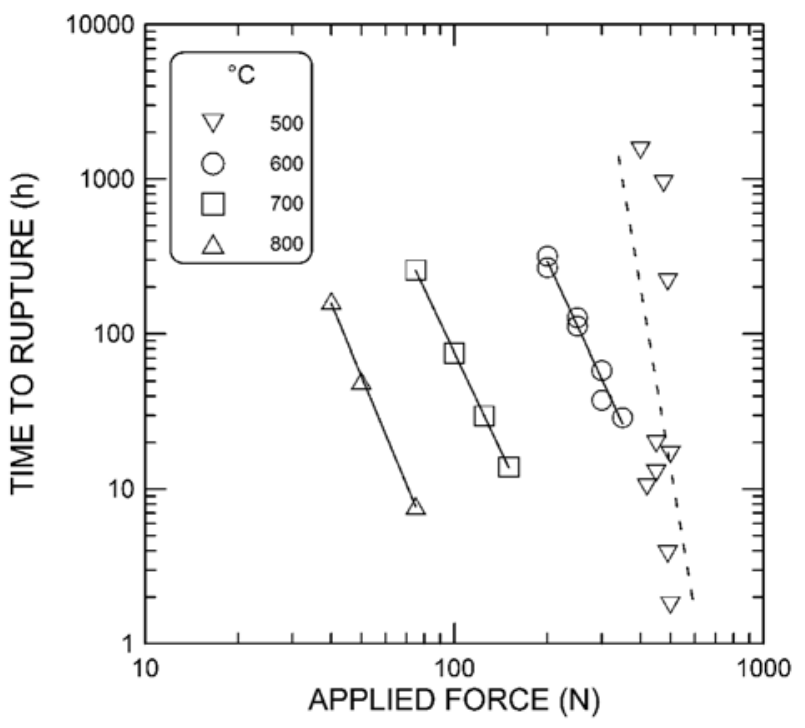

Fig. 4. Dependence of time to rupture on applied force.

$\mathrm{D}_{3}$ temperature of $500{ }^{\circ} \mathrm{C} n_{\mathrm{R}}$ is about -12 .

The fractographs of 3 specimens after the tests at 500, 700, and $800^{\circ} \mathrm{C}$ are shown in Fig. 5. The first examined specimen tested at $500^{\circ} \mathrm{C}$ exhibits clearly several radial cracks as shown in Figs. 5a,b. Such cracks are characteristic for low ductility alloys and transgranular brittle fracture with typical facet morphology shown in Fig. 5c. The fracture of the second specimen tested at $700^{\circ} \mathrm{C}$ in Figs. 5 d,e shows signs of much higher ductility, there is a characteristic circular crack and cap that is detached from the specimen. The necking is extremely narrow in this case except for a small location on one side where the cap has been detached at last. In this location shown in Fig. 5f there are still signs of transgranular fracture with facets. This can be most probably attributed to a static fracture (detachment of the cap) during the cool down or removal of the specimen from the jig. The third specimen tested at $800^{\circ} \mathrm{C}$ in Figs. $5 \mathrm{~g}$, h shows again a characteristic circular crack resulting in a cap that is detached from the specimen. The necking is extremely narrow and the fracture shown in Fig. 5i has a ductile transgranular morphology. Image of the deformed but not ruptured disc from $800^{\circ} \mathrm{C}$ interrupted test at time $t_{\mathrm{i}}=81 \mathrm{~h}$ is shown in Figs. 6a,b. There are not any signs of macroscopic crack present in the specimen at deflection $u_{\mathrm{i}}=$ $1.7 \mathrm{~mm}$. The rupture deflections $u_{\mathrm{R}}$ in the range of 2.5 to $3 \mathrm{~mm}$ are confirming very good ductility of the alloy.

\section{Discussion}

The conversion of force in small punch creep test to applied stress in conventional uniaxial creep test is 

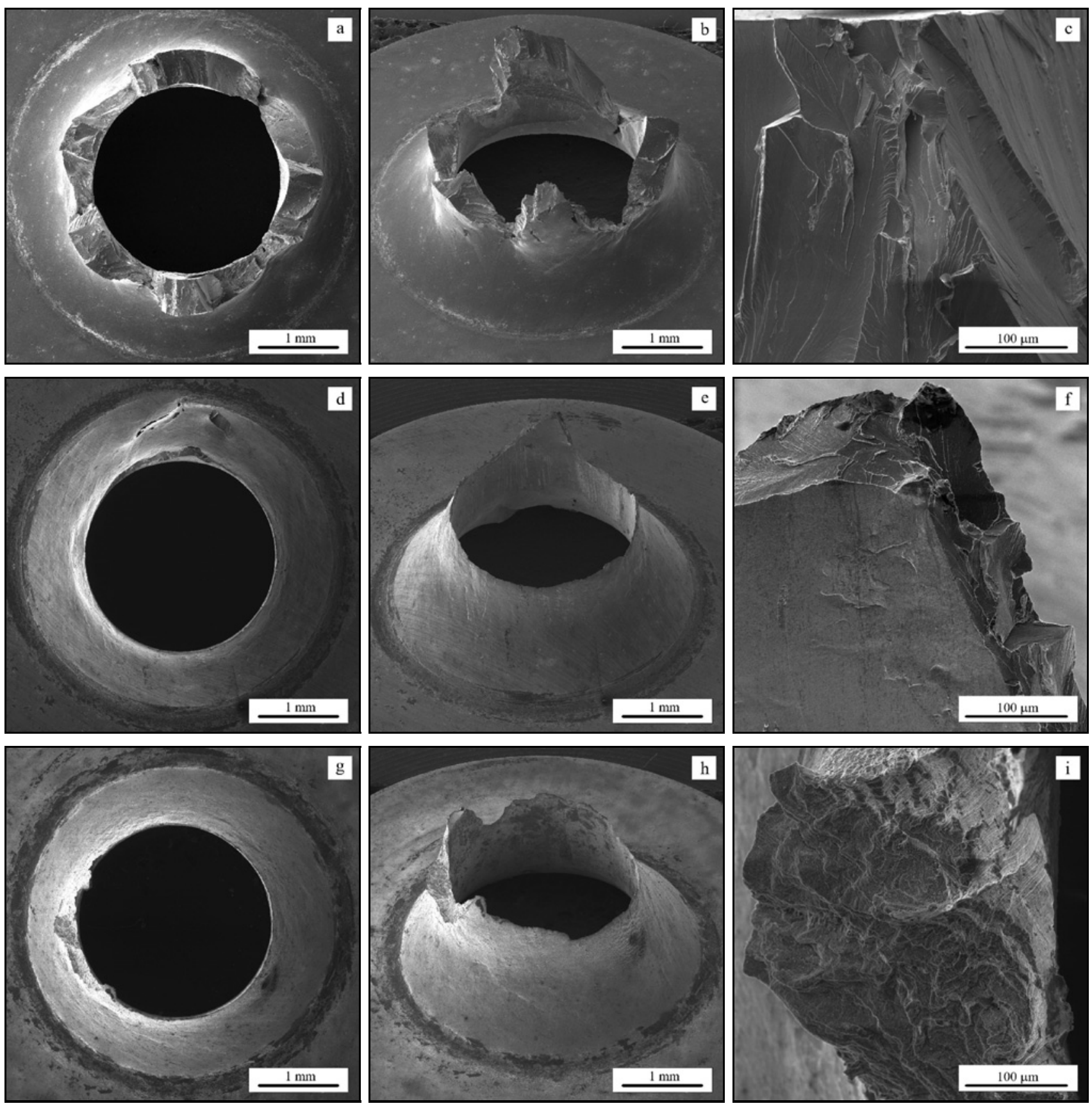

Fig. 5. Fractographs of ruptured specimens tested at $(\mathrm{a}-\mathrm{c}) \mathrm{T}=500^{\circ} \mathrm{C}, F=450 \mathrm{~N}, t_{\mathrm{R}}=19.5 \mathrm{~h} ;(\mathrm{d}-\mathrm{f}) T=700^{\circ} \mathrm{C}, F=$ $100 \mathrm{~N}, t_{\mathrm{R}}=75 \mathrm{~h} ;(\mathrm{g}-\mathrm{i}) \mathrm{T}=800^{\circ} \mathrm{C}, F=50 \mathrm{~N}, t_{\mathrm{R}}=50 \mathrm{~h}$.

usually based on a comparison of tests of the same time to rupture. In the preliminary European Code of Practice [27], a rough estimate of the relationship between force $F$ in small punch test and stress $\sigma$ in the conventional test is made using the Chakrabarty membrane stretch model [28]:

$$
F / \sigma=3.332 k_{\mathrm{SP}} r^{-0.2} R^{1.2} h_{0},
$$

where $r$ is the radius of lower die $(2 r=d$ in Fig. 1),
$R$ is punch radius, and $h_{0}$ is the initial thickness of the disc. $k_{\mathrm{SP}}$ is a correlation factor introduced to adjust the theoretical model to the experimental results. It was shown later [29] that this factor is a function of load. Therefore, for the prepared European small punch standard a fully empirical force-to-stress conversion model was chosen as the preferred methodology. The force-to-stress ratio was optimized for all available uniaxial, and small punch creep data. It was shown that the ratio is dependent on the value of de- 

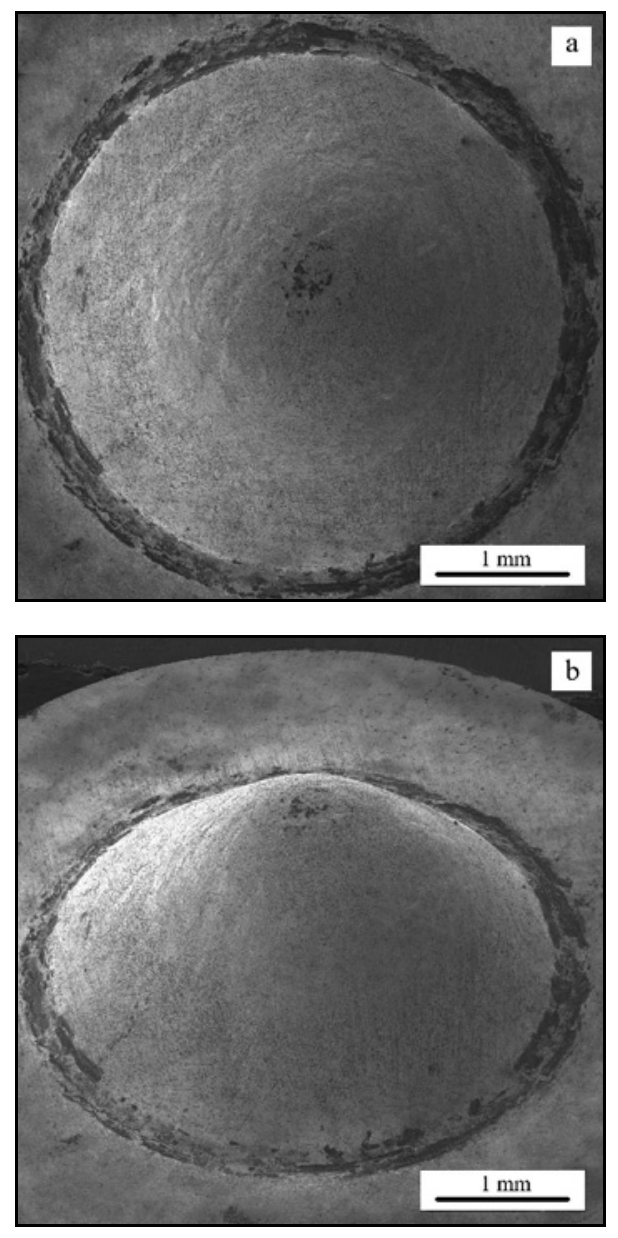

Fig. 6. Deformed specimen after interrupted test $t_{\mathrm{i}}=81 \mathrm{~h}$, $T=800^{\circ} \mathrm{C}, F=40 \mathrm{~N}, u_{\mathrm{i}}=1.70 \mathrm{~mm}$; (a) view on outer bottom specimen surface and (b) perspective view.

flection $u_{\mathrm{m}}$ measured at the location of the minimum deflection rate. The optimized formula is then

$$
\frac{F}{\sigma}=1.9162 u_{\mathrm{m}}^{0.6579}
$$

Comparison of the dependence of time to rupture in present small punch creep (SPC) test on equivalent stress calculated using Eq. (4) (open symbols) versus the same dependence reported for uniaxial creep tests (UAC) (closed symbols) [23] is given in Fig. 7. Fitted lines are drawn for uniaxial data using the exponential function as suggested by Kratochvíl et al. [23]. The agreement of uniaxial data and recalculated small punch data in the $\mathrm{B} 2$ range of temperatures is excellent. On the other hand, the results in $\mathrm{D}_{3}$ range $\left(500^{\circ} \mathrm{C}\right)$ do not match well. This is not surprising because the empirical formula Eq. (4) is based entirely on the results of ductile steels while the present alloy is evidently brittle in the $\mathrm{D}_{3}$ state. Primary cracks initiate from the centre of small punch specimens in

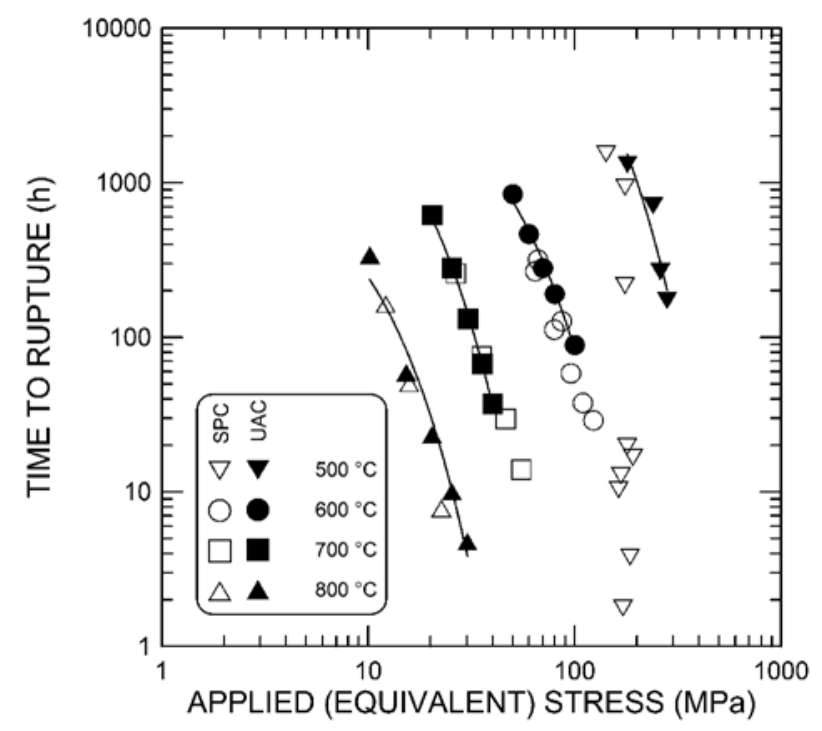

Fig. 7. Dependence of time to rupture in small punch tests and uniaxial creep tests on calculated equivalent stress and applied stress, respectively.

brittle materials. In ductile materials, the strain at the contact boundary is more important than that at the disc centre [30]. That is why the position of the contact boundary is used for calculation of the equivalent stress in terms of Eq. (3), moreover, such calculation fails in case of brittle cracks propagating from the centre.

Substantially less effort was devoted to finding the conversion of deflection rate in small punch creep test to strain rate in a uniaxial creep test. The relevant relationship for P91 was published by Ma et al. [31], but it was obtained for the ball of $2.4 \mathrm{~mm}$ in diameter. The standard mentioned above also includes a formula for transforming the measured minimum deflection rate, $\dot{u}_{\mathrm{m}}\left(\mathrm{mm} \mathrm{h}^{-1}\right)$, to the appropriate minimum creep rate, $\dot{\varepsilon}_{\mathrm{m}}\left(\mathrm{h}^{-1}\right)$,

$$
\dot{\varepsilon}_{\mathrm{m}}=0.3922 \dot{u}_{\mathrm{m}}^{1.1907}
$$

The calculated values of the minimum creep rate from the present small punch data are confronted with measured minimum creep rates in Fig. 8. The powerlaw relationship is applied for fitting the uniaxial data in conformity with the previous paper [23]. Though the agreement is acceptable in B2 range, it is less suitable than in the case of time to rupture (Fig. 7). The calculated values in $\mathrm{D}_{3}$ range again do not obey the measured ones.

The following procedure can be proposed to improve the conversion of the minimum deflection rate to the minimum creep rate: It is well known that the relation between minimum rate and time to rupture is valid for both uniaxial creep test [32] and small punch 


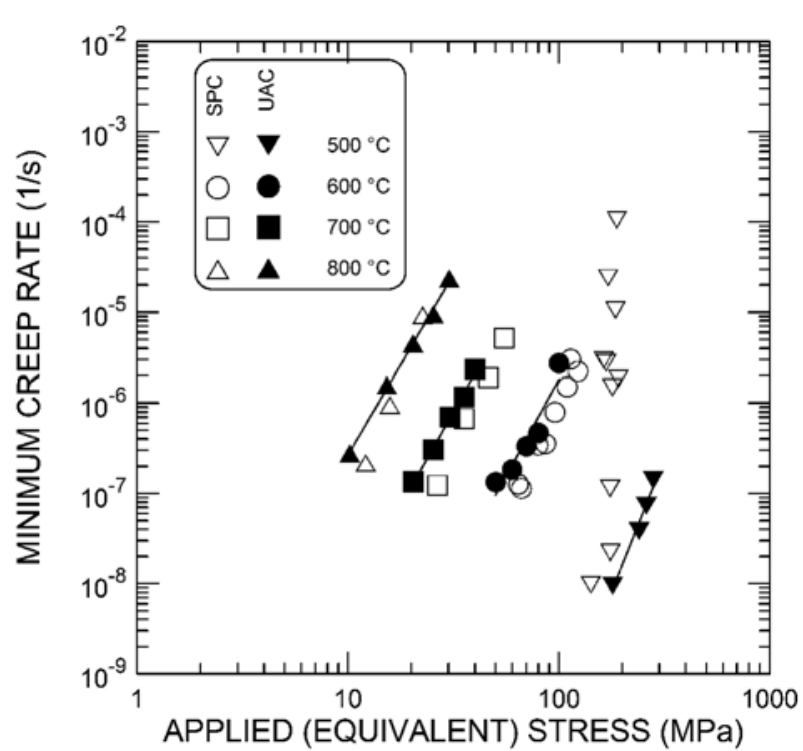

Fig. 8. Dependence of equivalent minimum creep rate in small punch tests and uniaxial creep tests on calculated equivalent stress and applied stress, respectively.

creep test [33]. This is illustrated in Figs. 9a,b. Note a completely different behaviour in $\mathrm{D}_{3}$ range. The dependences in $\mathrm{B} 2$ range can be described by the following simple equations

$$
\begin{aligned}
& \log t_{\mathrm{R}}=C_{1}-\log \dot{u}_{\mathrm{m}}, \\
& \log t_{\mathrm{R}}=C_{2}-\log \dot{\varepsilon}_{\mathrm{m}}
\end{aligned}
$$

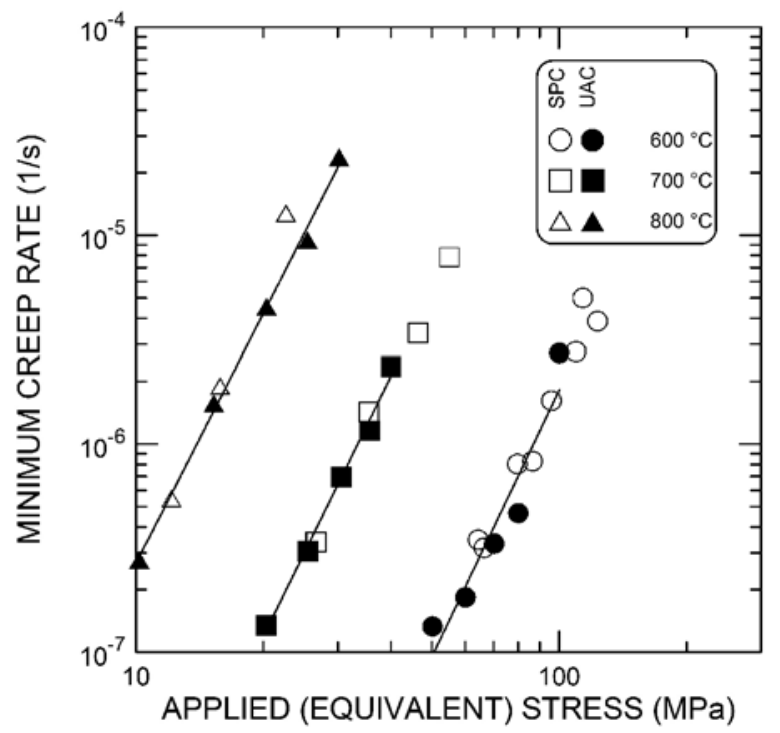

Fig. 10. Dependence of minimum creep rate in small punch tests calculated using Eq. (8) and measured in uniaxial creep tests on applied stress.

where $C_{1}$ and $C_{2}$ are constants. Their values can be found by regression analysis: $C_{1}=-0.0176$ (valid for displacement $u$ in mm) and $C_{2}=-0.455$. The resulting relationship between minimum creep rate and minimum deflection rate is then:

$$
\dot{\varepsilon}_{\mathrm{m}}=0.365 \dot{u}_{\mathrm{m}}
$$

Figure 10 illustrates the ability of Eq. (8) to con-

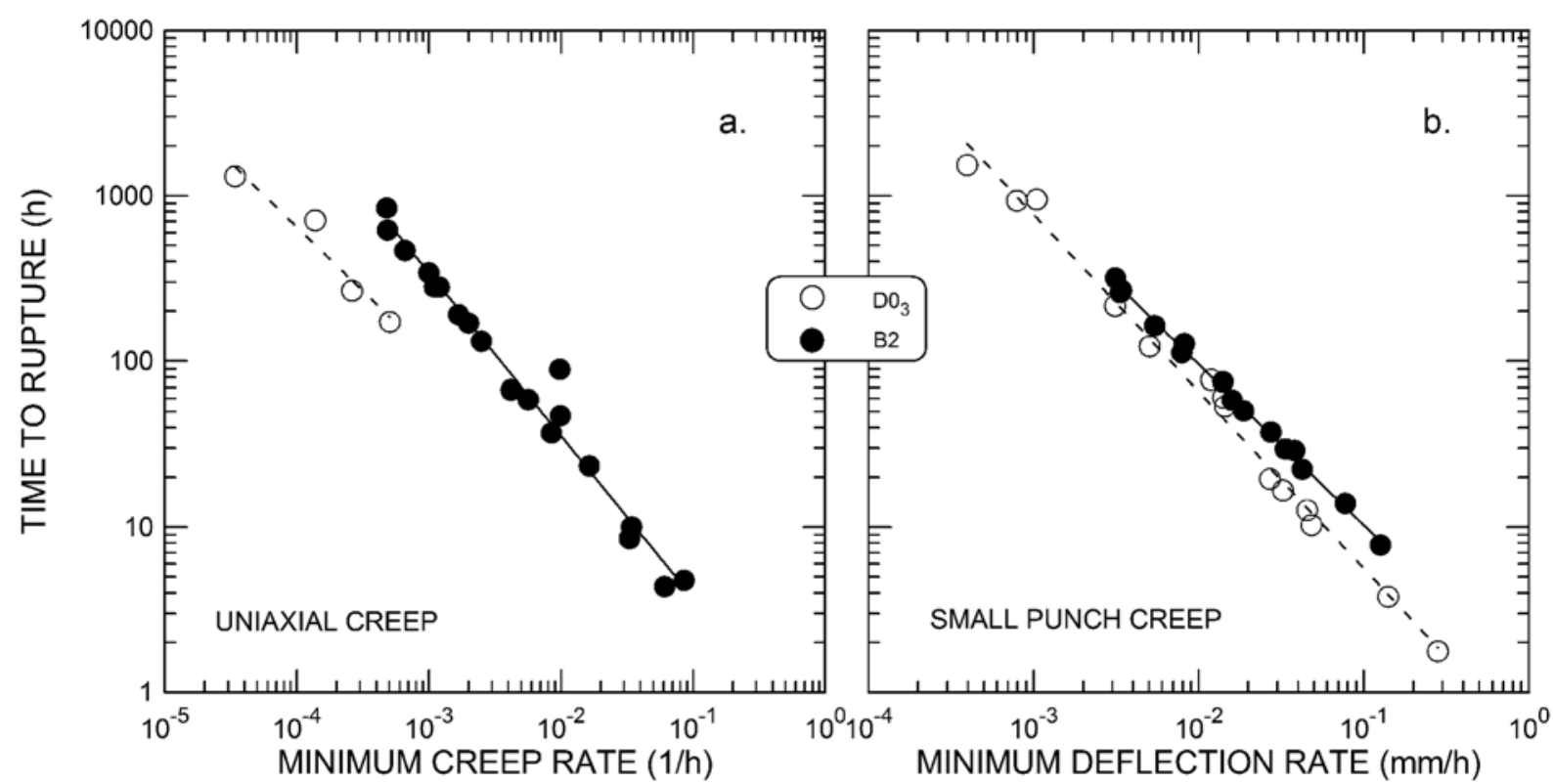

Fig. 9. Dependence of time to rupture on minimum creep and minimum deflection rate in (a) uniaxial creep test and (b) in small punch creep test, respectively. 
vert the deflection rate obtained in small punch test into equivalent creep strain rate. Caution should be used when transposing the equation to another material because it was deduced by including the data from only the present alloy.

\section{Conclusions}

1. The dependences of the minimum deflection rate and the time to rupture on the applied force follow similar dependences obtained in uniaxial creep tests of the same alloy.

2. The observed diversities of small punch tests can be explained by the existence of different crystal lattices occurring at different temperatures. This is manifested, e.g., by splitting the Monkman-Grant relationship into two lattice-sensitive dependences.

3. The force applied in the small punch test can be successfully converted into the equivalent applied stress using the empirical formula suggested by the new European standard for small punch testing.

4. The new standard is likely to extend the utilization of the small punch test in the design of new prospective alloys.

5. Procedure for comparison of minimum deflection rate and minimum creep rate is presented. This is based on empirical observation of Monkman-Grant relationship.

\section{Acknowledgements}

Financial support from the Czech Science Foundation (project No. 17-22139S) is gratefully acknowledged. Professor P. Kratochvíl (Charles University, Prague) kindly supplied the experimental material.

\section{References}

[1] Sauthoff, G.: Intermetallics. Weinheim, VCH Verlagsgesellschaft 1995 .

[2] Liu, C. T., Stringer, J., Mundy, J. N., Horton, L. L., Angelini, P.: Intermetallics, 5, 1997, p. 596. doi:10.1016/S0966-9795(97)00045-9

[3] Stoloff, N. S.: Mater. Sci. Eng. A, 258, 1998, p. 1. doi:10.1016/S0921-5093(98)00909-5

[4] Morris, D. G., Muńoz-Morris, M. A., Chao, J.: Intermetallics, 12, 2004, p. 821. doi:10.1016/i.intermet.2004.02.032

[5] Palm, M.: Intermetallics, 13, 2005, p. 1286. doi:10.1016/j.intermet.2004.10.015

[6] McKamey, C. G., Maziasz, P. J.: Intermetallics, 6, 1998, p. 303. doi:10.1016/S0966-9795(97)00104-0

[7] Lapin, J.: Materials Letters, 58, 2004, p. 3007. doi:10.1016/i.matlet.2004.05.029

[8] Michalcová, A., Senčekova, L., Rolink, G., Weisheit, A., Pešička, J., Stobik, M., Palm, M.: Materials and
Design, 116, 2017, p. 481.

doi:10.1016/j.matdes.2016.12.046

[9] Rouse, J. P., Cortellino, F., Sun, W., Hyde, T. H., Shingledecker, J.: Mater. Sci. Technology, 29, 2013, p. 1328. doi:10.1179/1743284713Y.0000000278

[10] Dyson, C. C., Sun, W., Hyde, C. J., Brett, S. J., Hyde, T. H.: Mater. Sci. Technology, 32, 2016, p. 1567. doi:10.1080/02670836.2015.1132536

[11] Altstadt, E., Ge, H. E., Kuksenko, V., Serrano, M., Houska, M., Lasan, M., Bruchhausen, M., Lapetite, J.-M., Dai, Y.: J. Nucl. Mater., 472, 2016, p. 186. doi:10.1016/i.jnucmat.2015.07.029

[12] Komazaki, S., Kato, T., Kohno, Y., Tanigawa, H.: Mater. Sci. Eng. A, 510-511, 2009, p. 229. doi:10.1016/j.msea.2008.04.132

[13] Gülçimen, B., Hähner, P.: Mater. Sci. Eng. A, 588, 2013, p. 125. doi:10.1016/j.msea.2013.09.029

[14] Holmström, S., Auerkari, P., Hurst, R., Blagoeva, D.: Mater. Sci. Technology, 30, 2014, p. 63. doi:10.1179/1743284713Y.0000000311

[15] Petzová, J., Březina, M., Kapusňák, M., Kupča, L.: In: Proceedings of ASME 2015 Pressure Vessels and Piping Conference. Ed.: Walsh, D. New York, American Society of Mechanical Engineers 2015, Paper No. PVP2015-45539. doi:10.1115/PVP2015-45539

[16] Matocha, K., Hurst, R.: Key Engineering Materials, 734, 2017, p. 3. doi:10.4028/www.scientific.net/KEM.734.3

[17] Bruchhausen, M., Austin, T., Holmström, S., Altstadt, E., Dymacek, P., Jeffs, S., Lancaster, R., Lacalle, R., Matocha, K., Petzova, J.: In: Proceedings of ASME 2017 Pressure Vessels and Piping Conference. Ed.: Walsh, D. New York, American Society of Mechanical Engineers 2017, Paper No. PVP2017-65396. doi:10.1115/PVP2017-65396

[18] McKamey, C. G., Liu, C. T.: Scripta Metall. Mater., 24, 1990, p. 2119. doi:10.1016/0956-716X(90)90496-4

[19] Yangshan, S., Zhengjun, Y., Zhonghua, Z., Haibo, H.: Scripta Metall. Mater., 33, 1995, p. 811. doi:10.1016/0956-716X(95)00282-Z

[20] Hotař, A., Kratochvíl, P.: Kovove Mater., 40, 2002, p. 45.

[21] Hakl, J., Vlasák, T., Kratochvíl, P.: In: Proceedings of the Conference Metal 2001. Ed.: Prnka, T. Ostrava, Tanger 2001, Paper No. 79.

[22] Dobeš, F., Milička, K.: Kovove Mater., 43, 2005, p. 66.

[23] Kratochvíl, P., Šedivá, I., Hakl, J., Vlasák, T.: Kovove Mater., 40, 2002, p. 124.

[24] Kassner, M. E., Pérez-Prado, M.-T.: Progr. Mater. Sci., 45, 2000, p. 1. doi:10.1016/S0079-6425(99)00006-7

[25] Karlík, M., Kratochvíl, P., Janeček, M., Siegl, J., Vodičková, V.: Mater. Sci. Eng. A, 289, 2000, p. 182. doi:10.1016/S0921-5093(00)00913-8

[26] Stein, F., Palm, M.: Int. J. Mater. Res., 98, 2007, p. 580. doi:10.3139/146.101512

[27] CEN, Small Punch Test Method for Metallic Materials. Part A: A Code of Practice for Small Punch Creep Testing. Part B: A Code of Practice for Small Punch Testing for Tensile and Fracture, CEN Workshop 21 document, Brussels, 2006. 
[28] Chakrabarty, J.: Int. J. Mech. Sci., 12, 1970, p. 315. doi:10.1016/0020-7403(70)90085-8

[29] Blagoeva, D.: Development of a Residual Lifetime Prediction Methodology for Creep and Fracture Behaviour of Ferritic-Martensitic Steels using Small Punch Testing Technique. [Ph.D. Thesis]. Pisa, Universita di Pisa 2009.

[30] Li, Y., Sturm, R.: In: Proceedings of the ASME 2008 Pressure Vessels and Piping Conference. Ed.: Hasegawa, K. New York, American Society of Mechanical Engineers 2008, Vol. 3, p. 739.

doi:10.1115/PVP2008-61437
[31] Ma, Y. W., Shim, S., Yoon, K. B.: Fatigue Fract. Eng. Mater. Struct., 32, 2009, p. 951. doi:10.1111/j.1460-2695.2009.01394.x

[32] Monkman, F. C., Grant, N. J.: Proc. ASTM, 56, 1956, p. 593.

[33] Dobeš, F., Milička, K.: Mater. Sci. Eng., A336, 2002, p. 245. doi:10.1016/S0921-5093(01)01975-X 